\title{
Effect of Rosuvastatin on learning and memory in scopolamine induced amnesia in Mice
}

\author{
Jayaraman Rajangam* and O Lavanya \\ Department of Pharmacology, Sree Vidyanikethan College of Pharmacy -Tirupati, 517501, Andhra Pradesh, India
}

\begin{abstract}
The present study was undertaken to investigate the effects of rosuvastatin (ROSS) on learning and memory on scopolamine (SCOP) induced amnesia in mice. Experiments were carried out on 20 adult albino mice, divided into 4 groups and the experimental animals were treated for 14 days with ROSS (10mg/kg.p.o).To induce amnesia, scopolamine $3 \mathrm{mg} / \mathrm{kg}$ ip was administered intraperitoneally. Cognitive skills of the animals were examined after the induction of amnesia by using elevated plus maze (EPM), Morris water maze (MWM). In EPM model, scopolamine received animals showed significant increase in transfer latency on day 7 and 14 when compared to control animals. Whereas piracetam and rosuvastatin received animals showed significant decrease $(\mathrm{p}<0.05)$ in transfer latency period when compared to scopolamine treated animals. In MWM test, rosuvastatin treatment showed significant decrease in escape latency period ( $\mathrm{p}<0.05$ ) when compared to scopolamine treated animals The results confirm that, scopolamine impaired learning and memory process in animals, whereas administration of ROSS significantly ameliorated scopolamine induced amnesia in both elevated plus maze and Morris water maze test as indicated by significant reduction ( $\mathrm{p}<0.05$ ) in transfer latency $(\mathrm{TL})(\mathrm{p}<0.05)$ and escape latency $(\mathrm{EL})$ respectively, hence it can be concluded that, that rosuvastatin improves cognitive functions against scopolamine-induced amnesia in mice.
\end{abstract}

\section{Introduction}

Memory is one of the vital ability of an individuals to record events, preserve information and retain them over short and long periods [1]. Amnesia is mainly characterized by loss of memory ability sufficiently and interferes with one's occupational or social activities and it is one of the common causes which leads to a condition called dementia which is a progressive neurodegenerative disorder associated with loss of neurons in distinct brain areas. Although there are several neuronal pathways and neurotransmitters were involved in the process of learning and memory and on the basis of experimental as well as clinical evidences, central cholinergic system is considered as the most important neurotransmission system which is involved in regulation of cognitive functions $[2,3]$. Hence, experimental studies and treatment approaches focused on drugs that increase levels of acetylcholine in the brain to compensate for losses of cholinergic function of the brain.

Only limited therapeutic interventions are available to reduce the incidence of dementia due to decline of learning and memory of individuals. Cholinesterase inhibitors, calcium channel blockers and glutamate antagonists are few classes of pharmacological agents which are being clinically explored to reduce symptomatically the impact of cognitive dysfunction associated with vascular dementia [4]. However, an agent that should improve both endothelial dysfunction and associated dementia still need to be explored. Very recently, the focus has been directed towards statins (HMG-CoA reductase inhibitors), which are most widely prescribed drugs for dyslipidemias [5].

Statins in additions to their cholesterol lowering action are known to possess many cholesterol independent actions including favorable effect on vascular endothelium [6]. Moreover, there is an emerging data indicating that statins exert neuroprotective and antioxidant actions. Statins have been shown to reduce the risk of ischemic stroke and related memory impairment by a variety of mechanisms [7].
Epidemiological studies have suggested that individuals above 50 years of age, who were receiving statins, had a substantially lowered risk of developing dementia, independent of the presence or absence of untreated hyperlipidemia, or exposure to non-statin lipid-lowering drugs [8]. However, there are conflicting observations regarding the effect of statins on cognitive functions. Although, there are a few studies showing cognitive decline [9], some studies showing no effect on memory [10,11], yet few studies suggest improvement of cognitive functions with statin therapy. However, the potential of statins in dementia of vascular origin still remains to be explored and deserves further investigation this field of research was found to be fertile. Therefore, the present study aimed to investigate the effects of rosuvastatin on learning and memory in mice against scopolamineinduced amnesia.

\section{Materials and methods}

\section{Animals and experimental conditions}

Adult male albino mice (weighing 20-30 g) were kept in polypropylene cages with free access to food and water, under standardized housing conditions (natural light-dark cycle, temperature of $23 \pm 10 \mathrm{C}$, relative humidity of $55 \pm 5 \%$ ), were used. After 7 days of adaptation to laboratory conditions, the animals were randomly assigned to different experimental groups and each group comprised

${ }^{\star}$ Correspondence to: Jayaraman Rajangam, Department of Pharmacology, Sree Vidyanikethan College of Pharmacy Tirupati, 517501. Andhra Pradesh, India, Tel: 0877-2236711; E-mail: jayaraam81@gmail.com

Key words: rosuvastatin, learning and memory, elevated plus maze, morris water maze, scopolamine

Received: March 29, 2018; Accepted: April 21, 2018; Published: April 25, 2018 
of 5 animals, all tests were performed between 09.00-15.00 hours. The experiments on animals were conducted in accordance with the internationally accepted guidelines for laboratory animal use and the experimental protocols were duly approved by the institution animal ethics committee ((SVCP/IAEC/I-003/2015-16) of Sree Vidyanikethan College of Pharmacy, Tirupati, AP, India.

\section{Drugs, chemicals and instruments}

Scopolamine bromide and Piracetam was obtained from Sigma (St. Louis, USA). Rosuvastatin and piracetam were suspended in $1 \%$ carboxy methyl cellulose (CMC) and administered per orally to respective groups whereas scopolamine was dissolved in $0.9 \%$ physiological saline and administered intraperitoneally to animals.

\section{Experimental design}

Experiments were carried out on adult albino mice. A total of 20 albino mice (20-30gm) were used in this experiment. The mice were divided into four groups of five animals each $(n=5)$. Amnesia was induced by scopolamine injection $(3 \mathrm{mg} / \mathrm{kg}$, i.p.) $30 \mathrm{~min}$ before the behavioral experiments. All groups except the control group received scopolamine. Piracetam is used as standard drug (Table 1). The cognitive and memory functions of the rats were assessed half an hour after the administration of scopolamine $[12,13]$.

\section{Neurotoxicity test}

Neurotoxicity of the drug rosuvastatin was assessed by chimney test. This test was carried out over the period of $45 \mathrm{~min}$ and the animals were subjected to prior training. a Pyrex glass tube $(25 \mathrm{~cm}$ long and $3 \mathrm{~cm}$ diameter) marked at a point $20 \mathrm{~cm}$ from its base; a mouse was introduced at the end, nearest the mark. When the animal reached the other end of the tube, the tube was moved to the vertical position and immediately the mouse tried to climb backwards. The ability of mice to leave the tube within $1 \mathrm{~min}$ was considered to indicate the lack of neurotoxic properties of the test drug. Screened mice were injected intraperitoneally as per the experimental design and were tested after $45 \mathrm{~min}$ as described above [14,15].

\section{Assessment of Activity}

Elevated plus-maze test (EPM): Mice were placed individually at the end of open arm. The time for each mouse to move to the closed arm was considered as transfer latency (TL) and was noted for $90 \mathrm{sec}$. On the first day of study, mice were allowed to move freely to explore the apparatus for at least $10 \mathrm{~min}$. TL recorded on 1st day was acquisition (learning) and $7^{\text {th }}$ and $14^{\text {th }}$ day TL reflects the retention / consolidation (memory) for learning [15].

Morris water maze test (MWM): MWM represent more specific test of spatial memory. MWM apparatus consists of a large circular pool with $150 \mathrm{~cm}$ in diameter and $45 \mathrm{~cm}$ in height, filled with water to a depth of $30 \mathrm{~cm}$ at $28 \pm 1^{\circ} \mathrm{C}$. The water was made opaque by addition of small quantity of titanium dioxide. The tank was then divided into four equal quadrants (Q1, Q2, Q3 and Q4) by using threads. There was a hidden platform (white in color with a diameter of $10 \mathrm{~cm}$ ) kept at the center

Table 1. Experimental design of the study

\begin{tabular}{|c|c|c|}
\hline Group No. & Drug treatment (14 Days) & Dose \\
\hline & Control & NS $(0.9 \%)$ \\
\hline & Scopolamine & $3 \mathrm{mg} / \mathrm{kg}$, i.p. \\
\hline & Piracetam + Scopolamine & $400 \mathrm{mg} / \mathrm{kg}, \mathrm{p}$. o. $+3 \mathrm{mg} / \mathrm{kg}$, i.p. \\
\hline & Rosuvastatin + scopolamine & $10 \mathrm{mg} / \mathrm{kg}$. p.o $+3 \mathrm{mg} / \mathrm{kg}$, i.p. \\
\hline
\end{tabular}

of the $4^{\text {th }}$ quadrant $1 \mathrm{~cm}$ below. Mice were subjected to 4 consecutive trials before the experiment on each day of study ( $7^{\text {th }}$ and $14^{\text {th }}$ day). The animal was released in the water facing towards the wall of the tank allowed to escape to the hidden platform and further allowed to remain there for $20 \mathrm{sec}$ and the escape latency (ELT) was recorded. ELT is the time taken by the animal from getting dropped in to the tank to escape on to the platform (Cut off period is 120sec) [16].

Rotarod test: The rotarod apparatus consisted of a rotating bar suitably machined to provide grip strength. Latency to fall animals from the bar is automatically recorded in seconds. Mice were initially selected for the ability to remain on the rotating bar rotating at a constant speed of $25 \mathrm{rpm}$ for at least two consecutive 180 seconds trials before the test day. On the test day animals were placed individually as per the experimental design in each compartment and their fall of time were noted $[17,18]$.

\section{Statistical analysis}

The statistical analysis was carried out by one-way analysis of variance (ANOVA). The values are represented as mean \pm SEM. Comparison of mean values of different groups treated with different dose levels of extracts and positive controls were estimated by Turkey's Multiple Comparison Test. $\mathrm{p}<0.05$ was considered significant.

\section{Results}

\section{Chimney test}

Results from chimney test suggest that there were no neurotoxic effects were observed with rosuvastatin ( $10 \mathrm{mg} / \mathrm{kg}$ i.p.) and it has no impact on motor coordination in mice at the investigated dose and the animals were able to leave the tube with in $1 \mathrm{~min}$.

\section{Effect of Rosuvastatin on transfer latency in EPM}

In the study, time required to reach closed arm from open arm by each animal was considered as transfer latency period. From the results, In EPM model, scopolamine received animals showed significant increase in transfer latency (60.44 Sec on day 7 and 63.68 on day 14) when compared to control animals ( $44.53 \mathrm{Sec}$ on day 7 and $30.69 \mathrm{Sec}$ on day 14).Whereas piracetam and rosuvastatin received animals showed significant decrease in transfer latency period on day 7 (50.24 Sec) and $14(38.11 \mathrm{Sec})$ when compared to scopolamine treated animals $(62.44$ Sec on day $7 \& 60.68 \mathrm{Sec}$ on day 14 respectively) (Figure 1). The results confirm that, scopolamine impaired learning and memory process in animals, whereas the rosuvastatin $(10 \mathrm{mg} / \mathrm{kg}$ p.o $)$ treatment had significantly reduced these impairments on mice.

\section{Rota rod test}

In rota rod test, between control and experimental group on day 7 and 14 there was no significant observables difference were noticed in the fall off time among different experimental groups are given in Table 2 .

\section{Effect of Rosuvastatin on escape latency in MWM}

In MWM test, results show that scopolamine received animals showed significant increase in escape latency (103.56 Sec on day 7 and 101.51 on day 14) when compared to control animals (74.43 Sec on day 7 and $62.63 \mathrm{Sec}$ on day 14 respectively). Whereas in piracetam and rosuvastatin treatment had significantly decrease the latency period on day 7 and 14 (Figure 2). In case of rosuvastatin treatment the decreased transfer latency period was 80.56 for day $7 \& 38.11$ 


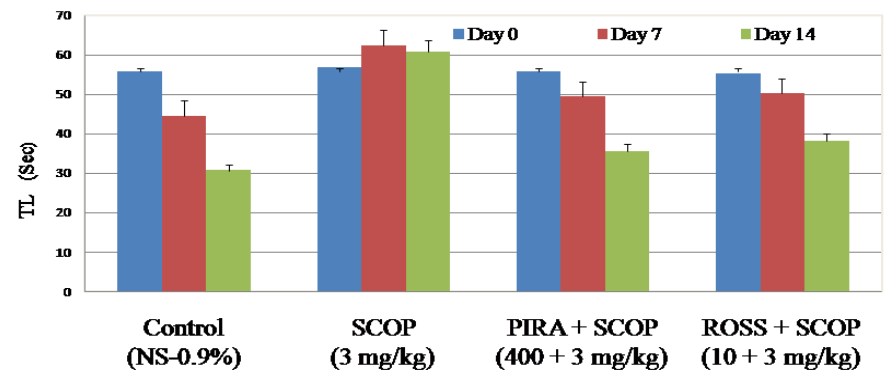

Figure 1. Effect of Rosuvastatin on transfer latency $(\mathrm{Sec})$ in elevated plus maze

Table 2. Effect of ROSS on fall of time in rotarod against scopolamine induced amnesia in mice

\begin{tabular}{|l|c|c|c|}
\hline \multirow{2}{*}{ Groups } & \multicolumn{3}{|c|}{ Fall of time (Sec) } \\
\cline { 2 - 4 } & Day 0 & Day 7 & Day 14 \\
\hline Control - NS (0.9\%) & $114.54 \pm 3.36$ & $124.54 \pm 2.87$ & $122.81 \pm 1.57$ \\
\hline Scopolamine (3 mg/ kg, i.p.) & $119.69 \pm 5.85^{\text {ns }}$ & $121.47 \pm 1.61^{\text {ns }}$ & $121.65 \pm 3.61^{\text {ns }}$ \\
\hline $\begin{array}{l}\text { Piracetam + Scopolamine } \\
(400 \mathrm{mg} / \mathrm{kg}, \text { p.o. }+3 \mathrm{mg} / \mathrm{kg}, \text { i.p. })\end{array}$ & $118.36 \pm 4.65^{\mathrm{ns}}$ & $125.27 \pm 3.36^{\mathrm{ns}}$ & $121.38 \pm 1.57^{\mathrm{ns}}$ \\
\hline $\begin{array}{l}\text { Rosuvastatin + scopolamine } \\
(10 \mathrm{mg} / \mathrm{kg}, \text { p.o. }+3 \mathrm{mg} / \mathrm{kg}, \text { i.p. })\end{array}$ & $115.57 \pm 4.54^{\mathrm{ns}}$ & $119.62 \pm 5.64^{\mathrm{ns}}$ & $128.64 \pm 2.34$ \\
\hline
\end{tabular}

Number of animals $(\mathrm{n}=5)$ : Values are mean \pm SEM: ${ }^{*} \mathrm{p}<0.05,{ }^{* *} \mathrm{p}<0.01 \& * * * \mathrm{p}<0.001$ When compared to control and scopolamine treated groups ; ns: Non-significant

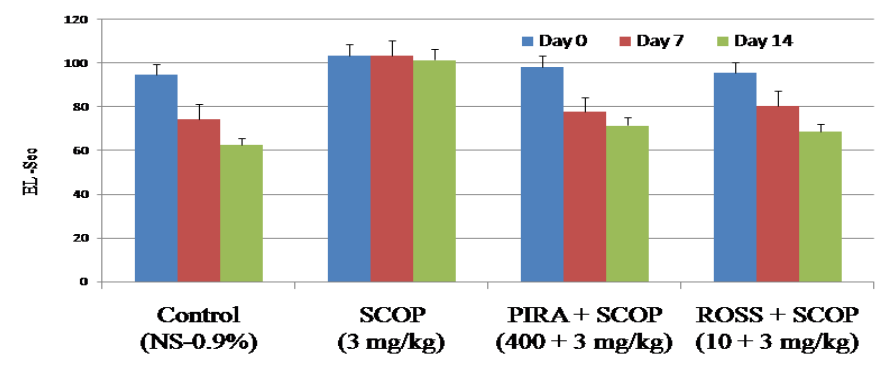

Figure 2. Effect of Rosuvastatin on escape latency $(\mathrm{Sec})$ in Morris water maze

for day 14 when compared to scopolamine treated animals (103.56 Sec on day 7 and 101.51 on day 14 respectively). The results confirm that, scopolamine impaired learning and memory process in animals, whereas administration of ROSS significantly ameliorated scopolamine induced amnesia in Morris water maze test as indicated by significant reduction $(\mathrm{p}<0.05)$ in escape latency $(\mathrm{EL})$ against scopolamine-induced in mice.

\section{Discussion}

In the present study, the anti-amnesic effect of Rosuvastatin on the scopolamine-induced memory impairment was evaluated using different exteroceptive behavioral models like Morris water maze (MWM), elevated plus maze tests etc. These tasks have been extensively used to measure learning and memory in different animal models particularly, behavioral manipulations in rodents $[19,20]$.

Piracetam is a nootropic agent, used as standard in the present study and the dose of piracetam, rosuvastatin has been taken from the earlier studies [21]. Results of the present study suggests that mice treated with scopolamine showed more prolonged transfer latency in EPM and prolonged escape latencies than the control animals. In contrast, acute administration of rosuvastatin showed significant memory enhancing activity $(\mathrm{p}<0.05)$ in the scopolamine-induced amnesia in animals.

Some recent studies challenge the viability of scopolamine as a cognitive impairer by questioning the relation of the alterations in the memory tasks to loco motor effects, instead of memory disruption [22]. Our obtained results from the velocities of animals in the MWM test also the time animals remain on rod in the rotarod test showed no significant differences between locomotor activities of different groups. So, these results demonstrate that rosuvastatin can improve learning and memory function of mice against scopolamine-induced amnesia.

Results from chimney test reveals that, all the mice were able to leave the tube with in $1 \mathrm{~min}$ which indicates that there were no neurotoxic effects were observed with rosuvastatin $(10 \mathrm{mg} / \mathrm{kg}$ p.o $)$ and it has no impact on motor coordination, muscle grip strength in the rotarod test against scopolamine induced amnesia model.

\section{Conclusion}

In conclusion, results from the present study demonstrates that, scopolamine impaired learning and memory process in animals, whereas administration of ROSS significantly ameliorated scopolamine induced amnesia in both elevated plus maze and Morris water maze test as indicated by significant reduction in transfer latency (TL) and escape latency (EL) respectively, hence it can be concluded that, that Rosuvastatin improves cognitive functions against scopolamineinduced in mice. However, the beneficial effects and mechanism responsible for improved learning and memory showed by rosuvastatin remain unclear and deserves further investigations.

\section{Declarations}

Conflict of interest: The authors declare that they have no competing interests.

Acknowledgements: The authors are grateful to Dr.C.K. Ashok Kumar Principal, Dr. S. Mohanalakshmi Vice Principal and the management of Sree Vidyanikethan College of pharmacy for providing the necessary facilities to carry out the research work. This research received no specific grant from any funding agency in the public, commercial, or not-for-profit sectors.

\section{References}

1. Dunning J, During MJ (2003) Molecular mechanisms of learning and memory. Expert Rev Mol Med 5: 1-11. [Crossref]

2. Vanderwolf CH (1988) Cerebral activity and behavior: Control by central cholinergic and serotonergic system. International Rev Neurobiol 30: 225. [Crossref]

3. Blokland A (1995) Acetylcholine: a neurotransmitter for learning and memory? Brain Res Brain Res Rev 21: 285-300. [Crossref]

4. Korczyn AD, Kalvach P, Bornstein ND (2005) Vascular dementia. J Neurol Sci 2003 $1-2$.

5. Parle M, Singh N (2007) Reversal of memory deficits by Atorvastatin and Simvastatin in rats. Yakugaku Zasshi 127: 1125-1137. [Crossref]

6. Miida T, Takahashi A, Ikeuchi T (2007) Prevention of stroke and dementia by statin therapy: Experimental and clinical evidence of their pleiotropic effects. Pharmacol Ther 113: 378-93. [Crossref]

7. Vaughan CJ (2003) Prevention of stroke and dementia with statins: Effects beyond lipid lowering. Am J Cardiol 91: 23B-29B. [Crossref]

8. Austen B, Christodoulou G, Terry JE (2002) Relation between cholesterol levels, statins and Alzheimer's disease in the human population. J Nutr Health Aging 6: 377382. [Crossref]

9. Wagstaff LR, Mitton MW, Arvik BM, Doraiswamy PM (2003) Statin-associated memory loss: analysis of 60 case reports and review of the literature. Pharmacotherapy 23: 871-880. [Crossref]

10. Muldoon MF, Barger SD, Ryan CM, Flory JD, Lehoczky JP, et al. (2000) Effects of lovastatin on cognitive function and psychological well-being. Am J Med 108: 538546. [Crossref] 
11. Bayten SH, Alkant M, Ozeren M, Ekinci M, Akgun A (2006) Fluvastatin alters psychomotor performance and daily activity but not the spatial memory in rats. Tohoku J Exp Med 209: 311-320. [Crossref]

12. Gouliaev AH, Senning A (1994) Piracetam and other structurally related nootropics. Brain Res Brain Res Rev 19: 180-222. [Crossref]

13. Lenegre A, Chermat R, Avril I, Steru L, Porsolt R (1988) Specificity of piracetam's antiamnesic activity in three models of amnesia in the mouse. Pharmacology Biochemistry Behavior 29: 625-629.

14. Mandhane SN, Aavula K, Rajamannar T (2007) Timed pentylenetetrazol infusion test a comparative analysis with s.c.PTZ and MES models of anticonvulsant screening in mice. Seizure 16: 636-644. [Crossref]

15. Joshi H, Parle M (2006) Zingiberofficinale: evaluation of its nootropic effect in mice. Afr J Trad CAM 3: 64-74.

16. Lavinsky D, Arteni NS, Netto CA (2003) Agmatine induces anxiolysis in the elevated plus maze task in adult mices. Behav Brain Res 141: 19-24.
17. Kulkarni SK. Handbook of experimental pharmacology 3rd edition 119:135.

18. Taiwe GS, Bum N, Dimo T (2010) Antidepressant, myorelaxant and Anti-anxiety like effects nauclea latifolia smith (Rubiaceae) roots extract in murine models. International J pharmacology 6: 364-371.

19. Oh JH, Choi BJ, Chang MS, Park SK (2009) Nelumbo nucifera semen extract improves memory in rats with scopolamine-induced amnesia through the induction of choline acetyltransferase expression. Neurosci Lett 461: 41-44. [Crossref]

20. Terry Jr AV (2000) Spatial navigation (water maze) tasks. In: JJ. Buccafusco (Eds), Methods of Behavior Analysis in Neuroscience. (2nd edition). Boca Raton (FL): CRC Press.

21. Georgieva-Kotetarova MT, Kostadinova II (2013) Effect of atorvastatin and rosuvastatin on learning and memory in rats with diazepam-induced amnesia. Folia Med (Plovdiv) 55: 58-65. [Crossref]

22. Klinkenberg I, Blokland A (2010) The validity of scopolamine as a pharmacological model for cognitive impairment: A review of animal behavioral studies. Neurosci Biobehav Rev 34: 1307-1350. [Crossref]

Copyright: (C2018 Rajangam J. This is an open-access article distributed under the terms of the Creative Commons Attribution License, which permits unrestricted use, distribution, and reproduction in any medium, provided the original author and source are credited. 